\title{
PERIPECIAS DEL HÉROE EN EL MITO CONTEMPORÁNEO
}

ENTREVISTA CON ERNESTO PABLO MOLINA AHUMADA

HERO'S PERIPETEIA IN CONTEMPORARY MYTH

Interview with Ernesto Molina Ahumada

\section{PERIPÉCIAS DO HERÓI NO MITO CONTEMPORÂNEO}

Entrevista com Ernesto Molina Ahumada

\section{Omar Alejandro Murad \\ (Universidad Nacional de Mar del Plata) muradoma@gmail.com \\ Emiliano Aldegani \\ (Universidad Nacional de Mar del Plata) emilianoaldegani@gmail.com}

Recibido: $16 / 01 / 2021$

Aprobado: 16/01/2021

El Dr. Ernesto Pablo Molina Ahumada es Doctor en Letras por la Universidad Nacional de Córdoba. Profesor Titular en la Facultad de Lenguas y Profesor Asistente en la Facultad de Filosofía y Humanidades de la Universidad Nacional de Córdoba. Se ha desempeñado como Vicedirector de la Escuela de Historia (FFyH, UNC) y Presidente a Cargo de la Asociación Argentina de Retórica. En sus investigaciones ha reflejado el potencial performático de los nuevos medios incorporando categorías del estudio de la semiótica al análisis de nuevas plataformas de entretenimiento videolúdico, pero también se ha dedicado al análisis de las figuras de lo heroico en la literatura. Ha sido galardonado con el Premio de la Academia Argentina de Letras 2004 por su desempeño académico.

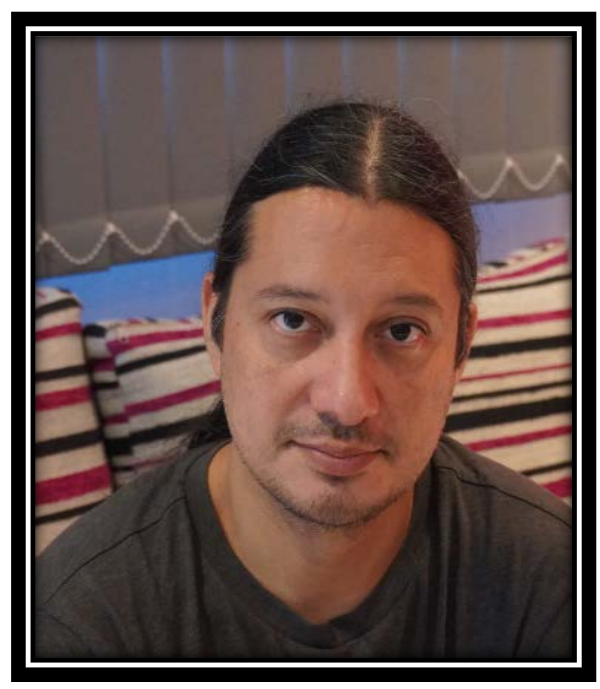

1. Al observar su trabajo se advierte un interés particular puesto en el papel del héroe en la cultura contemporánea desde una concepción que recupera la noción de mito, y también una recuperación de las posibilidades de agencia que anidan en los ambientes virtuales. ¿Qué relaciones cree que cabría establecer entre estos mitos contemporáneos y los roles asignados al héroe con el antiguo concepto de "ficción"?

El héroe mítico, al menos el de la épica, ha funcionado como una especie de figura con valor estructural en torno a la cual, muchas veces, ya sea de forma metafórica o metonímica, se han condensado una serie 
de valores y concepciones históricas y sociales. En ese sentido, el mito ha tenido una función social fundamental como directriz de orientación simbólica, política y social. Es decir, ha sido eficiente como dispositivo simbólico y semiótico para la construcción de cierto consenso social.

La ficción ha sido, creo, el ecosistema en el que esa figura heroica ha podido desplegar su potencial significativo, pues es en el marco de posibilidades verosímiles generadas por la mecánica ficcional que esa figura ha logrado no sólo extender su sentido sino también permear otros ámbitos por la capacidad de traslación o traducción metafórica que facilita la literatura.

La pregunta acerca de antigua mitología y mitología contemporánea nos retrotrae al viejo interrogante acerca de si los griegos creían realmente en sus mitos. Y la respuesta es, en cierto modo, ambivalente, porque tal como ha demostrado el trabajo sobre el mito que desarrolla Hans Blumenberg como algunos de los hallazgos de Detienne, es preciso reconocer que sobre el mito han operado distintas interpretaciones según las condiciones históricas que han guiado determinadas funciones. En el caso de la tragedia griega del siglo $\mathrm{V}$ a. de $\mathrm{C}$., por ejemplo, sería dable pensar que sólo a partir de la despotenciación del poder divino conferida a la palabra del mito y su manipulación poética fue posible ver en el héroe más que un modelo a imitar o evitar, una metáfora. Cuando Aristóteles lidia en su Poética con la diferenciación acerca del lugar del héroe en la épica, la tragedia y la comedia, alude en cierto modo no sólo a lo que las ficciones deben hacer, sino también al margen de posibles tratamientos de lo mítico en su época.

Para hablar de los mitos contemporáneos, entonces, creo que debiéramos pensar en una nueva torsión de ese material sumamente maleable y devenido una especie de reservorio de la memoria cultural de Occidente a partir de las múltiples operaciones que las sociedades han hecho y seguirán operando sobre ese material. Algo de esto es lo que Lotman y la Escuela de Tartu aportan al estudio del mito: desde la Semiótica de la Cultura, el mito aparece como una cantera inagotable de "informatividad cultural" porque es capaz de referir a asuntos, estructuras narrativas o temas que son por todos conocidos, pero que no dejan sin embargo de ofrecer la posibilidad de generar nuevos sentidos o revelar matices no abordados previamente. En eso radica la capacidad de lo que otros estudiosos del mito, como Gilbert Durand, F. Monneyron y J. Thömas, han denominado el carácter palingenésico o de múltiples y periódicos nacimientos de los mitos.

La pregunta entonces acerca de los roles del héroe en los mitos contemporáneos está signada por esta premisa de partida acerca del origen inhallable (e incluso irrelevante) de una figura modélica original de héroe en la antigüedad, porque incluso quienes llamamos "antiguos" habían ya operado modificaciones sobre una materia preexistente. Sin embargo, una diferencia fundamental entre los mitos que hemos edificado contemporáneamente y aquellos regulados por el concepto de ficción en la antigüedad clásica, es cierta preponderancia de una dimensión laica y de la injerencia de lo divino en torno a la aventura del héroe; y por otra parte la importancia y posibles resoluciones que adopta la última instancia de lo Joseph Campbell a llamado "el viaje del héroe".

Con respecto a lo primero, podríamos notar que la mayoría de los superhéroes de la épica occidental contemporánea a través del cómic, las series de televisión, el cine y últimamente el videojuego, aparecen desprovistos de mandatos de alguna divinidad y sus destinos no están atados al capricho o voluntad de los dioses, con lo cual cobra relevancia su propia labor y lo industriosos o ingeniosos que puedan llegar a ser para forjar su propio derrotero. Esa es una gran diferencia acerca de lo verosímil que distancia nuestras ficciones del héroe épico de La Ilíada o los héroes de la tragedia griega clásica. No se trata en el caso contemporáneo, sin embargo, de héroes desligados o sin algún tipo de ligazón con fuentes de poder, protohéroes o cualquier otra entidad que en un escalafón de poderío esté por encima del héroe, sino del lugar -o más precisamente del no lugar- al que ha sido relegado lo divino en el conjunto de relaciones que provocan la verosimilitud de un relato. Esa condición, que es epocal y que delimita lo que queda dentro y fuera de lo que Coleridge designaba como "suspensión momentánea de la incredulidad" al definir la ficción, brilla por su ausencia en los mitos edificados en la actualidad en donde el héroe deambula sin esta presencia protectora o hado funesto, autonomía que trae aparejada como su 
correlato una mayor responsabilidad sobre sus propias acciones y estar expuesto continuamente al conflicto frente a sus propios actos.

La otra cuestión que he señalado tiene que ver con la importancia que adquiere la última parte de la peripecia heroica, lo que Campbell denomina el regreso al mundo de partida, que por lo general no es un destino apetecible ni frecuente en ficciones contemporáneas. La reintegración del héroe a su comunidad de partida tiene un efecto reparador y conciliador en las ficciones anteriores, que está en sintonía con el carácter conservador y de encauzamiento social que desempeñó el mito en algunas sociedades de la antigüedad. Pero desaparecidas las estructuras políticas y lógicas sociales que vehiculizaban esos mitos y favorecieron su traducción ficcional en un enorme repertorio de figuras y relatos que resultaban eficientes para justificar esa dominancia, queda la pregunta acerca de qué sentido comunicar con esa peripecia heroica y qué imagen de mundo se construye mediante esa estructura narrativa. Esta pregunta es central porque echa por tierra cualquier idea acerca del mito como letra muerta, como ornamento estético o como narrativa vaciada, para recuperar más bien la productividad e inagotabilidad informativa de la que hablábamos antes con Lotman, al plantear que el mito sigue vigente como estructura narrativa capaz de hacer comprensible, mediante la articulación de elementos ficcionales, situaciones o estados de la "realidad".

Joseph Campbell, en El héroe de las mil caras, señala que aquella estructura recurrente que él denomina monomito heroico, culmina con la reintegración, y que ese es el destino deseable del héroe, a riesgo si no de no cumplir su destino psicosocial. En este punto, creo que las premisas psicoanalíticas de Campbell le impiden reconocer que convivimos muy probablemente durante gran parte del siglo XX (tengo mis dudas si nuestro primer héroe derrotado no es Quijote, a inicios del XVII) con héroes que fracasan sistemáticamente en su intento de reintegración o retorno al mundo de partida $\mathrm{y}$, si lo hacen, ese retorno no es valorado como un éxito sino todo lo contrario: o bien es fracaso el no haberse podido librar del influjo del mundo de origen; o bien ese retorno es sospechado de complicidad; o bien confirma la insuficiencia heroica para cambiar ese mundo de partida y por lo tanto lo infructuoso que resulta emprender cualquier proeza heroica.

Las variaciones y posibilidades de resolución de la peripecia de los héroes contemporáneos pueblan algunas de las ficciones más notables del siglo XX, tanto en la literatura como en el cine, por lo que no hace falta referirlas aquí. Lo que sí podemos mencionar es el modo interesante en que esta nueva mítica contemporánea en torno al héroe fracasado o, más bien, en torno al héroe que fracasa, no descarta al mito como estructura de base sino que discute esta tercer instancia, precisamente la que sintetiza y concentra la carga valorativa acerca del papel del héroe frente al mundo de partida que ha intentado o que considera necesario cambiar. En mi investigación en torno a un grupo de novelas españolas y argentinas de autores contemporáneos, lo que he intentado demostrar es que esta nueva mítica del fracaso no aparece en esas novelas centrada exclusivamente en la figura heroica, sino en el contexto de inoportunidad o infravaloración de acciones que, en otro contexto, hubiesen resultado quizá efectivas. Lo que señala esto, desde mi lectura, es que el cambio en el contexto de expectativas y representaciones sociales que alimentan lo legible ficcional estaría señalizando una profunda crítica a un tiempo que es antiheroico, no en el sentido usual que suele asociar el término a un conjunto de valores negativos, sino en el sentido de ser un tiempo que no brinda chance, oportunidad ni relevancia a la ocurrencia de lo heroico como acción éticamente orientada y comprometida con el beneficio de la comunidad. Fracasar en el contexto de esta nueva mítica resulta, por lo tanto, un elogio a la no renuncia a ciertos valores que, a pesar de todo, el personaje protagonista sostiene.

Como dice Saer, de nada sirve pensar la ficción en clave negativa como aquello que no es realidad, sino que resulta más productivo reflexionar acerca de la ficción como un dispositivo que se sumerge y busca plasmar la complejidad de lo real. Las ficciones que transportan consigo este tipo de héroe y este mensaje aportan, creo yo, una crítica valiosísima a un presente que podríamos leer de manera distorsionada si lo viésemos, por ejemplo, desde los ojos triunfalistas de la épica cinematográfica hollywoodense o desde algunas series televisivas o videojuegos que prolongan esa épica. 


\section{2. ¿Los nuevos medios modifican nuestra percepción de la ficción como lo no real? ¿En qué sentido?}

Los nuevos medios pululan entre el doble efecto de un hiperrealismo y una ficcionalización de lo real, sumado al hecho de que quizá aquellos medios que gozaban de mayor prestigio a la hora de "captar" lo real, como la fotografía o cierto cine documental, hayan sido ubicados de un tiempo a esta parte (por efecto del giro digital en primer término y por la demostración de los alcances de software de edición en segundo término) en el banco de los sospechosos, junto a otros viejos conocidos que asumieron hace tiempo su estatuto ficcional, como la literatura o el arte. Desde esta lógica, tenemos hoy en día gracias a los avances en materia de óptica y compresión de imágenes digitales acceso a fotos detalladas, por ejemplo, de cualquier lugar del planeta a través de las pupilas de nuestros satélites, pero esas fotografías pueden falsear la realidad al ser ubicadas en el contexto narrativo de algo sin base empírica, como por ejemplo que hay armas de destrucción masiva en cierto territorio y sólo eso justifica su invasión.

Parto de la idea, como he referido con Saer, de que lo ficcional no es sinónimo de lo no real sino de aquello que por inverificable, multiplica al infinito las posibilidades de tratamiento de aquello que llamamos lo real. En ese sentido, algunos de los nuevos medios como la realidad virtual, magnifican y aproximan a la pupila aquello que reproducen digitalmente, pero el sentido que puede adoptar esa modelización de la realidad puede ser el de transmitir un mensaje mucho más intenso y cercano (corporalmente) del que podríamos experimentar si viéramos lo mismo en televisión, o bien banalizarlo y volverlo objeto de consumo al punto de dudar si lo que se observa no es un actuación o simulación. El cine interactivo, que parece vivir su momento revival gracias a algunos videojuegos de corte cinematográfico y algunas series televisivas que han reflotado el experimentalismo interactivo de Kinoautomat (1966-1967), podría ser pensado como otro nuevo medio, pero se trata en esencia de la realización técnica de ficciones cinematográficas de trama abierta gracias a las posibilidades que ofrece no sólo el lenguaje digital (ya la tecnología CD-ROM y la compaginación de fragmentos de video había hecho posible hacia 1990 la aparición del CD Interactivo), sino también el avance en materia de almacenamiento y compresión de video, la mejora en la infraestructura de conectividad y la apetencia por ficciones a la carta, por influjo (en relación a lo que plantea Alessandro Baricco en The Game) de cierta naturalización de la lógica interactiva de los videojuegos en la cotidianidad de la cultura contemporánea.

\section{3. ¿Qué consecuencias tiene afirmar que nuestra cultura tiene sus mitos contemporáneos? ¿Creemos en esos mitos?}

Considero que una de las principales consecuencias es asumir que no somos tan racionales como creíamos o como pretende mostrarnos cierta discursividad científica que, según el Gilbert Durand de $L a$ imaginación simbólica o bien de Ciencia del hombre y tradición, vendría a ser una nueva mitología de retórica antimitológica que desde el siglo XIX se entronizó como directriz imaginaria en la cultura. Sin pretender entrar en detalle acerca de Durand y su crítica a la racionalidad occidental iconoclasta y antimitológica, lo que quiero remarcar es el modo en que podríamos reconocer, si adoptáramos una perspectiva de extrañamiento acerca de nuestra propia cultura, el funcionamiento de lógicas y narrativas específicas del mito que aparecen trasladadas a otros terrenos y que resultan eficientes para comprehender ciertos fenómenos de la realidad. Por ejemplo, el relato del emprendedorismo que construye en torno al individuo aislado toda una épica del riesgo y los obstáculos para mostrar -en línea con el monomito de Campbell- un camino exitoso de superación y derrame de esas virtudes sobre el conjunto de la sociedad o, al menos, sobre aquellos pares que son capaces de "ver" el mundo a partir de esa ideología de lo "verdadero" (el dilema simplista de padre rico-padre pobre y otros relatos que reflotan el concepto de "cultura de la pobreza" de Oscar Lewis).

O podríamos pensar incluso en otras mitologías contemporáneas hoy en crisis, como la idea de globalización, entendida como ese estado óptimo, irrefrenable y positivo que expresa el logro mancomunado de lo humano en su búsqueda de una civilización al alcance de cualquiera, en cualquier lugar del globo. Claro está, como señala Baricco en Next, que ese gran relato épico no fue sino la inflamación retórica de algo que significó más bien la ampliación del mercado a escala planetaria y una 
expansión de las posibilidades de movilidad del capital nunca antes visto, al punto de que esa movilidad implicó también el hallazgo de oasis o paraísos a donde el fisco no pudiera alcanzar ese dinero librecirculante.

Podríamos multiplicar los ejemplos, pero a lo que apunto es a mostrar cómo estos mitos, es decir estos relatos que construyen narraciones no sólo explicativas sino organizativas y justificativas del presente, siguen operando como directrices simbólicas en nuestras sociedades contemporáneas, a la par o más allá de cualquier visión laica o cientificista que podamos asumir también. Es decir, hablar de mitos contemporáneos no nos priva de racionalidad o civilización, como podría parecer si lo pensamos al modo en que lo hicieron los primeros antropólogos a inicios de la disciplina, sino más bien dimensionar la complejidad de los entramados simbólicos, semióticos, políticos y sociales en los que estamos inmersos y el peso que tienen los mecanismos ficcionales - no exclusivos de la literatura y del arte, como queda claro- a la hora de vehiculizar y posicionar a esos relatos como eficaces para una descripción -que es construcción- de la realidad.

\section{Utilizando como propone en varios trabajos el concepto de performance para pensar la relación entre la peripecia heroica y las acciones transmitidas por la memoria de la cultura ¿qué relaciones se pueden establecer entre el ritual que es la base pragmática que anida en el mito y el uso que propone del concepto de performance?}

Es cierto que el concepto de performance, al menos según se propone en los estudios actuales de autores como Richard Schechner y Gustavo Blázquez, me ha resultado sumamente útil para abordar algunas de las problemáticas que surgen al estudiar el funcionamiento del mito en textos contemporáneos como en el caso del videojuego, frente al cual las herramientas de la crítica literaria pueden resultar insuficientes y los aportes de otras disciplinas quizá tangenciales. El concepto que maneja Schechner, que es un teórico del teatro, entiende por performance aquella secuencia de conductas, acciones programadas y pautadas que acontecen dos o " $n$ " veces pero nunca por primera vez, es decir, alude con ello a cierto carácter paradojal a la vez que productivo en las prácticas pues, al mismo tiempo que parecieran estar repitiendo algo del mismo modo que una vez anterior, alteran indefectiblemente ese origen supuesto a través de su reactualización y su re-escenificación. Esta idea es extrapolada por el antropólogo argentino Gustavo Blázquez para pensar los modos en que resultan legibles en tanto performances ciertas prácticas o conductas sociales, de tal modo que el concepto es desplazado para asumirlo como lente de enfoque o perspectiva de estudio de los fenómenos sociales: ¿qué pasaría si leemos como una performance un acto escolar, una marcha o una sesión de videojuego? ¿Qué prácticas se juegan allí y de qué manera se tensionan las prácticas anteriores a partir de esa nueva ocurrencia de la acción de jugar?

Hay mucha discusión teórica acerca de la relación entre mito y ritual, algunas quizá basadas en la distinción discurso/práctica derivada de la distinción saussureana entre lengua y habla, o discusiones preocupadas en establecer una relación genética y cronológica acerca de qué fue primero, si el ritual o el mito. En cierta manera, la perspectiva de los estudios acerca de las prácticas sociales como performances hace irrelevante esa cuestión y la destierra de su ámbito de interrogantes, porque toda práctica es el acontecimiento por segunda vez de un origen tachado. Cuando Detienne señala que el dominio que abarca la mitología es siempre un "sitio provisorio" porque representa un significante disponible que cada época y cada visión de mundo crea a la medida de su saber pero presenta como copia fiel de la antigua mitología, refiere precisamente a esta operación a la que apunta el concepto de performance tal como lo manejo, que es la de subrayar el carácter relativo de un fenómeno, incluso cuando se edifica como fiel representación de una práctica memorizada.

Nuestras mitologías contemporáneas están llenas de referencias a rituales a los cuales dicen tributar. La utilidad del concepto y sobre todo la que posee metodológicamente asumir la performance como perspectiva de análisis, radica en atender no solamente a los puntos de reiteración y contacto con prácticas anteriores, sino a los matices de sentido, las desobediencias y las oportunidades creativas que se hacen visibles cuando asumimos que lo que acontece en determinada práctica restaura de manera 
creativa, única e irrepetible una práctica anterior, y por lo tanto, constituye una nueva práctica que merece nuestra máxima atención.

Hay otra cuestión interesante, ligada a esa especie de efecto secularizador de pensar en mitos en nuestro tiempo contemporáneo, y es la idea de ver rituales en prácticas actuales, a contrapelo de la intuición que podría sugerirnos la idea de que el rito, por anidar en el mito, es algo específico y anclado en un tiempo anterior, prestigioso y lejano según la definición de Mircea Eliade. El concepto de performance trastoca esa jerarquía para evidenciar la dimensión ritual en prácticas cotidianas que, al ser abordadas desde esta lente, ganan espesor mítico. Es decir que la llegada al mito es de manera inversa, pues no se parte de reconocer el mito y de allí deslindar el rito de base, sino de establecer como matriz de enfoque la performance, que revela los rituales que han convertido a ciertas prácticas cotidianas en formas mitificadas. Un buen ejemplo, como el que analiza Gustavo Blázquez, es el de los actos escolares, que son una instancia en los que podríamos decir se reproduce al pie de la letra ciertos eventos o acontecimientos de los héroes fundadores de la patria, pero que reinventa cada vez el acontecimiento, de modo tal que las copias de ese suceso no son la sucesión de un hecho original más sucesivas rememoraciones que lo tributan, sino el conjunto abierto de " $n$ " representaciones que lo restauran y reinventan indefinidamente.

Al combinar esta productividad del concepto de performance con el de ficción se obtienen resultados interesantes, porque las propias estructuras narrativas almacenadas por la memoria cultural y que animan muchos de nuestros relatos - como los del cine o los videojuegos bélicos, que se basan en cierta manera en la visión de la épica y la lógica antagonista del mito heroico en su lucha contra el mal - ganan sentido a partir de esta condición memoriosa y creativa a la vez que revela el concepto de performance bajo la piel de esas estructuras narrativas conocidas. Advertida la mirada de quien analiza, se trata entonces de reconocer y describir qué innovaciones y que nuevas ritualidades han sido habilitadas a través de esa actualización de la épica, a la vez que nominar nuevas mitologías fundamentadas en estos nuevos modos de hacer.

La perspectiva performática acerca de los fenómenos de la realidad invita, creo yo, a asumir cierta mirada de sospecha y extrañamiento frente a prácticas que reconocemos por que las hemos visto ya suceder, pero también re-conocemos en el sentido de que volvemos a conocer esas prácticas, porque asumimos que lo que allí sucede no es igual a lo anterior ni tampoco a lo que vendrá.

\section{La noción de performance permite en gran medida explorar la interacción entre las posibilidades de actuación del héroe en juegos en ambiente virtuales o videojuegos y el jugador, ¿cómo opera esta interacción en la producción de significado? ¿Qué posibilidades quedan para la innovación en este entramado?}

La pregunta acerca de los márgenes de innovación en los contextos en los cuales actuamos alude quizá a uno de los interrogantes centrales del mito desde la noche de los tiempos, que es el problema de la libertad y la medida de lo humano frente a la divinidad y el mundo circundante. Resulta curioso a la vez que hermoso que vuelva a surgir aquí y ligado al caso del videojuego, porque pone de manifiesto que más allá de los artefactos que hemos inventado para imaginar, algunas preguntas siguen inquietándonos.

La noción de performance me permite reconocer las múltiples posibilidades de actuación y su relación con prácticas anteriores que no son necesariamente de juego, pero que algunos videojuegos "restauran" en un contexto digital controlado en donde esas acciones no tienen efecto más allá del mundo ficcional. Disparar un arma, arrojar una lanza, acariciar a otro personaje, saltar, correr o atropellar a alguien conduciendo un automóvil son acciones no sólo permitidas sino requeridas por algunos juegos, y cuando hablamos de requisito no nos referimos solamente a la variable "genérica" de que un juego bélico necesita que disparemos, sino también a la necesidad de retroalimentación o feedback del videojuego en tanto programa informático, que es una particularidad que caracteriza a este tipo de texto digital. Teóricos como Espen Aarseth piensan el videojuego y otros cibertextos a partir del lugar preponderante que posee el operador humano y su papel imprescindible para el funcionamiento del texto. Claro que leer un libro implica cierta "interacción" del ojo y los dedos con el objeto libro, que requiere de ese 
recorrido por la página y ese pasar de hoja para producir sentido, pero Aarseth se refiere a un esfuerzo más relevante porque compromete mayor número de operaciones coordinadas corporales y cognitivas. Más allá de esta dependencia más marcada del videojuego con la retroalimentación con un ser humano, la pregunta acerca de qué impulsa a interactuar con estos textos podría estar en lo que el teórico Jesper Juul define como situación paradojal al jugar videojuegos, que es el desagrado o infelicidad que nos produce fallar y perder, pero también el desagrado que produce no poder superar un obstáculo. Juul señala que los videojuegos ofrecen posibilidades de experimentar y experienciar múltiples formas de acción en entornos de impacto emotivo controlado, es decir que la apuesta emotiva y las expectativas que invertimos al comprometernos con cierta ficción no tendrán efectos más allá de los límites de ese espacio-tiempo delimitado por el programa como mundo del juego. Esto es interesante también porque, como señalamos con el concepto de performance, la idea de secuencias de acciones que suceden " $n$ " veces representa un marco de posibles a ser exploradas y experimentadas, pero no deja de ser un conjunto de actuaciones previstas y permitidas de hecho por el código preexistente del programa.

Cuando hablamos de actuación heroica en el marco de un videojuego, incluso si el concepto de performance permite ver de qué manera se restaura la acción descripta en un mito, aludimos a la reflexión de Janet Murray y su idea de que no hay co-autoría ni margen de creación posible, sino variantes coreográficas de un repertorio que ha sido absolutamente previsto por el programa informático. Toda acción imprevista o que el código no pueda armonizar con la simulación de ese mundo virtual constituye un fuera de juego y conduce al error y detención del programa. En este sentido, las interacciones del héroe bajo el comando de quien juega representan una secuencia de acciones previstas que, con mayor o menor margen de movilidad, se desenvuelven dentro de un marco de opciones disponibles. Esta cuestión nos lleva a otra que tiene que ver con la doble orientación o el espesor que se acumula en la figura del avatar del juego. Por avatar entendemos la representación digital bajo forma de personaje de quien juega dentro del mundo virtual, modelizado por el programa informático. Se trata, en cierto modo, de un cascarón que funciona para "alojar" la voluntad de quien juega, voluntad que se traduce a partir de los comandos que introducimos mediante algún dispositivo de interface como el mouse, un joystick o el teclado. Ahora bien, habida cuenta de esta mecánica que genera un "espejo" digital pero que nos refracta en otro que es quien afronta en definitiva las consecuencias de nuestras acciones, ¿quién es el héroe en la ficción videolúdica? ¿Por qué se asume frecuentemente la primera persona al hablar ("me mataron", "morí", "me caí") a diferencia de otras ficciones en las que no asumimos ese grado de identificación? No tengo aún respuesta para esto pero sí la intuición de que el tipo de interacción que promueve el videojuego a partir de la generación de este enlace entre figura heroica y jugador/a representa modos de ser, estar y transitar las ficciones que ningún otro texto ha suscitado. Previsiblemente, este grado de inmersión y las posibilidades interactivas en estos espacios de actuación en los cuales actúa nuestro doble digital o avatar, representa un modo de producción inédito en la cultura que expande sin duda los límites de la ficción (por aquello que decíamos con Juul acerca de los márgenes de experimentación y experiencia que promueve), a la vez que hace posible una gama de efectos emotivos, éticos y empáticos a partir de esta tensión entre proximidad y distancia en el núcleo mismo de la relación entre héroe ficcional, avatar y quien juega.

¿Qué posibilidades quedan de innovación en este entramado? Todas las permitidas, lo cual es contradictorio si lo pensamos desde el punto de vista de la existencia de un límite y un número finito de opciones; pero resulta productivo si pensamos que a diferencia de estructuras univiarias o de trama cerrada a la que ficciones anteriores del cine y la literatura nos han acostumbrado, algunos videojuegos -no todos- ofrecen variantes narrativas en función de las interacciones, generando mayor inmersión y cierta idea de "responsabilidad" sobre el destino del héroe y de lo que acontezca en ese marco ficcional. Ninguna de estas dos opciones, por supuesto, implica innovación como podría hacerlo la figura de autor, sino márgenes de actuación en función de marcos interactivos más o menos permisivos y con mayor o menor incidencia de esas acciones en el mundo ficcional resultante. 
6. El potencial expresivo de nuevos medios tales como los entornos videolúdicos o el universo transmedia, presentan nuevos elementos a tomar en cuenta, por ejemplo las llamadas retóricas procedurales, los esquemas de bonificaciones y penalizaciones, las disonancias ludo-narrativas, entre otros. Pensando por ejemplo en juegos como los de David Cage a los que le ha prestado particular atención. ¿Qué elementos simbólicos se ponen en juego en este tipo de dispositivos culturales y en qué medida aportan a nuestra forma de modelizar la imagen que construimos del mundo? ¿Pueden constituir estas imágenes un elemento que se ponga en juego al desarrollar nuestras prácticas en la esfera social?

Los videojuegos creados por David Cage son un excelente ejemplo de lo que se puede hacer con videojuegos cuando quieren dejar de serlo. Digo esto porque el propio Cage ha señalado en algunas entrevistas que es un cineasta frustado y que lo que ha pretendido a través de su estudio (Quantic Dream) es la exploración de algunas búsquedas del cine interactivo a partir de las posibilidades estéticas y técnicas del videojuego. No se cansa tampoco de repetir en sus intervenciones que lo que considera clave en la poética de sus obras es la generación de emociones únicas e irrepetibles y que de lo que se trata es de colocar a quien juega en situaciones de difícil resolución, como la vida misma. Tras algunas declaraciones que tienen enorme validez estética pero son totalmente inconvenientes a los ojos de los inversores y productores de los juegos de Cage (Sony) -como fue el caso de sugerir que la mejor forma de jugar algunos de sus juegos, a pesar de la variedad de opciones narrativas y finales, era jugarlos una sola vez y quedarse con ese resultado como la expresión más genuina del sentido que se había decidido construir para esa historia- Cage tuvo que desdecirse acerca de este principio estético para mantener contentos a sus patrocinadores.

Comento esta anécdota porque es un buen ejemplo para responder a la pregunta. En primer lugar, porque los juegos de Cage aspiran a ser leídos como cine o como literatura: poseen narrativas complejas; profundidad psicológica de los personajes; tramas políticas de trasfondo y vertientes de géneros tan diversos como el policial, el fantástico y la ciencia ficción; y sobre todo porque por lo general sus obras presentan un margen reducido de interacciones que se limita en algunos casos a presionar una serie de teclas o botones que garantizan el desarrollo de la trama. Este punto en particular ha despertado algunas opiniones negativas entre críticos y usuarios quienes, como es previsible, acusan a los juegos de Cage de no ser videojuegos sino películas o dramas interactivos. No yerran en su apreciación inicial, aunque fallan en considerar que un buen videojuego no pueda funcionar al mismo tiempo en clave cinematográfica. En función de esta situación fronteriza de los juegos de Cage con la literatura, el cine y otras formas artísticas, considero que en sus obras hay una voluntad estética definida y una fuerte conciencia autoral que construye deliberadamente un universo simbólico a través de múltiples elementos, desde el uso de las gamas cromáticas a la ambientación de los escenarios (la lluvia en Heavy Rain, la nieve en Fahrenheit y Beyond: Two Souls), la particular atención a la banda sonora, el realismo en la expresividad de los rostros y movimientos corporales que hizo posible la técnica de captura y digitalización de movimiento desde Heavy Rain, en 2010.

Hay un par de elementos al respecto que me parece interesante remarcar acerca de esta cuestión: la primera tiene que ver con el establecimiento de un lapso de tiempo para interactuar y tomar decisiones en la mayoría de los juegos de Cage, en línea con su voluntad "realista" de someter a quien juega a experiencias verosímiles y de alto impacto emocional. A diferencia de otros juegos donde el tiempo de la diégesis ficcional se disocia del tiempo del juego y transcurrir sin hacer absolutamente nada no ocasiona ninguna penalidad, los juegos de Cage garantizan su dinamismo obligando a tomar decisiones en un lapso determinado de tiempo e incluso no elegir acarreará consecuencias. Un primer efecto de esta introducción del simbolismo del tiempo es hacer ingresar la idea de fatalidad y de inevitabilidad para modelizar un mundo ficcional que aloja, pero del cual no se saldrá indemne: transitarlo tiene consecuencias y asumir las consecuencias de nuestros actos constituye un primer elemento de contacto entre las ficciones de Cage y las lógicas no ficcionales del mundo de la vida que él pretende modelizar.

Un segundo elemento de alto valor simbólico tiene que ver con el rostro y la mirada de los personajes como condensadores de sentido y puertas en enlace empático. Desde el primero de sus juegos, Omikron, Cage introduce escenas de ruptura de cuarta pared en las cuales la figura heroica mira a cámara $\mathrm{y}$, 
eventualmente, dialoga con quien se encuentra del otro lado. Este recurso, que se potencia gráficamente a partir de la técnica de captura facial desde Heavy Rain, cobra relevancia fundamental en su obra más reciente, Detroit: Become Human, en la que abundan los primeros planos y las escenas de ruptura de cuarta pared. Hay muchos videojuegos que no muestran el rostro del héroe (como los juegos de disparo en primera persona o algunos RPG o juegos de rol), lo toman de espalda, desde alguno de sus hombros o de cuerpo completo pero sin detalles de sus expresiones. Creo que uno de los aciertos de Cage a la hora de generar impacto emotivo y empatía es hacernos mirar de frente el rostro de sus personajes y percibir con un grado de detalle abrumador los matices en sus miradas, su gestualidad, su parpadeo o el contoneo de su cabeza. Parte de la magnitud de la poética de Cage se encuentra en suscitar este encuentro con el avatar que, colocado como un espejo, provoca vértigo. El efecto de sentido que detecto tiene que ver en la profundidad humana que adquieren las ficciones de Cage, espesor que adensa el conjunto de asuntos que se narran y que, de no ser por esta aproximación del rostro del otro, podrían referir fácilmente a cualquier desconocido. Sin embargo, la identificación y situación de adyacencia y emparejamiento que provoca el primer plano puebla los videojuegos de Cage de personas con nombre y rostro, personajes que nos miran a veces impávidos pero otras atentos y preocupados desde el otro lado de la pantalla, aguardando conocer qué destino decidiremos para ellos.

A qué conduce todo esto, me he preguntado cuando he terminado los juegos de Cage. ¿Es que pueden los videojuegos cambiar nuestra forma de relacionarnos y mirar el mundo? Creo que al menos esa intención es explícita en David Cage, toda vez que ha expresado su voluntad de utilizarlos como vehículos de emociones y generadores de empatía, y como si hubiese llegado ya el momento de explorar otras formas de ficción, más inmersivas, interactivas y persuasivas que las anteriores; o como si las anteriores hubiesen resultado insuficientes para lograr el cometido de interesarnos y experimentar en primera persona lo que acontece con los otros. Creo que la búsqueda de Cage tiene que ver más con lo primero que con lo segundo, pues recorriendo sus obras se torna evidente la profunda relación que guardan estos videojuegos con la literatura, con el teatro, con el cine, con la fotografía y con otros lenguajes culturales a partir de los cuales se proyectan. El último título en particular, me parece revelador con respecto a esta cuestión desde el título mismo: Detroit: Become Human. ¿Quién debe volverse humano? ¿Algunos de los tres androides que protagonizan esta fábula de ciencia ficción, que nos coloca en la piel de robot en busca de autonomía y libertad? ¿O somos quienes jugamos, humanos, los que debemos refractarnos en la vivencia de esos androides para poder recuperar, tras ese tránsito, nuestra propia condición humana? Tal como se anuncia desde el menú de inicio del juego, Detroit no es un juego sino una experiencia y por allí transcurre el logro más acabado de este videojuego: suscitar marcos de experiencia y experimentación con impacto reflexivo y emotivo sobre prácticas que exceden el plano ficcional.

Concluyo con un pequeño comentario, tratando a la vez de no cometer spoiler. En algún momento del juego uno de los androides nos pedirá explícita y frontalmente su libertad. Liberarlo acarrea ciertas consecuencias y no hacerlo otras. Creo que los juegos de Cage hacen de estos momentos de tensión empática su principal ariete de batalla, planteando preguntas relevantes que, más allá del mundo del juego, empujan a responsabilizarnos ante la presencia e interpelación del otro. No creo que constituya sin embargo un objetivo pedagógico o moralizante, pues eso implica anularlos en tanto juegos, sino que es algo que logran por la combinación de múltiples elementos: arte, juego, poética autoral y formas de la ficción. Ficciones empáticas las he llamado alguna vez: creo que el nombre sigue siendo adecuado para pensar las obras de Cage. 